\title{
RESILIENCE: A NEW RESEARCH AREA IN POSITIVE PSYCHOLOGY
}

\author{
Jia-Yan PAN and Cecilia Lai Wan CHAN \\ University of Hong Kong, China
}

\begin{abstract}
This paper introduces a new research area in positive psychology - resilience. Two groups of definition of resilience and two generations of resilience research are described. Two critical components of resilience are analyzed and resilience studies in Asian societies are reviewed. Finally, the implications of the application of the concept and direction for future resilience research are proposed.
\end{abstract}

Key words: resilience, positive psychology

The current research paradigm in psychology has moved away from a psychopathology perspective to a positive psychology perspective which focuses on positive human strengths and resources. Resilience study is one of the new research areas that attempts to find out what works instead of what does not. It emerged from the challenge of a growing number of studies in the fields of psychology, psychiatry and sociology which question the notion that risk factors inevitably doom people to develop psychopathologies (Henderson \& Milstein, 2003). In the 1970s, a pioneering group of developmental scientists began to pay attention to the children at risk for psychopathology who nonetheless developed into persons who were healthy and functioned normally in their adulthood (Masten, 1999). These investigations inspired three decades of research on resilience in the West (Masten \& Reed, 2002).

\section{DEFINITION OF RESILIENCE}

Resilience is a concept that is difficult to define with no universally accepted definition in the literature. In the resilience literature, two common groups of definition can be identified: (1) resilience as a personal trait; (2) resilience as a process.

\section{Resilience as a Personal Trait}

This group of definitions assumes that resilience is a personal trait or a set of traits. Researchers define resilience as the human ability or capacity to bounce back from, overcome, survive, or successfully adapt to a variety of adverse conditions, or major or multiple life stresses (e.g. Grotberg, 2003; Kirby \& Fraser, 1997; Minnard, 2002; Norman, 2000). Resilience can be described as a relatively stable personal characteristic or a set of

Correspondence concerning this article should be addressed to Jiayan Pan, Department of Social Work and Social Administration University of Hong Kong (e-mail: Jiayan@hkusua.hku.hk). 
characteristics (Liem, James, O’Toole, \& Boudewyn, 1997), which not only develops from life adversity but also grows from the experience of everyday life stress. Rirkin and Hoopman (1991) defined resilience as "the capacity to spring back, rebound, successfully adapt in the face of adversity, and develop social, academic, and vocational competence despite exposure to severe stress or simply to the stress that is inherent in today's world" (cited in Henderson \& Milstein, 2003, p. 7). It is clear from this definition that every person needs to develop resilience. Based on this definition, those who have resilience would be expected to have a much greater chance of thriving when life circumstances are difficult (Lopez, Prosser, \& Edwards, 2002).

From the perspective of this group of definition of resilience, human beings are no longer viewed as victims who suffer from adverse conditions; rather, they can be viewed as survivors who have the ability and strength to overcome adversity and life stress and achieve positive adaptation outcomes. Resilience suggests human strength and growth, yet resilience is different from "posttraumatic growth" because the latter involves an upward movement beyond the pretraumatic level of adaptation, while resilience assumes psychological growth that may or may not occur after adversity (Miller, 2003). Resilience can be considered to occur if the person returns rapidly to a previous state following trauma or negative life events (Bolig \& Weddle, 1988, cited in Holaday \& McPhearson, 1997).

\section{Resilience as a Process}

This group of definition describes resilience as a dynamic process of positive or successful adaptation despite the experience of adversity, trauma, threats, or stressful life events (e.g. Block \& Block, 1980; Liddle, 1994; Luthar et al., 2000a; Luthar \& Ziegler, 1991; Masten, Best, \& Garmezy, 1990; Rutter, 1990). According to Fonagy, Steele, Steele, Higgitt and Target (1994), resilience is not a set of individual attributes born or acquired during development. Rather they view resilience as a set of social and intrapsychic processes which is an interactive combination of individual, family, social and cultural environments. This set of processes represents the interaction between person and environment, in which individuals under adverse conditions utilize internal and external resources to achieve positive adaptation. There are two basic components in this group of definitions. One is that the individual must experience situations that carry a high risk for the development of psychopathology (Luthar et al., 2000a). The second is the generation and maintenance of positive adjustment in the face of adverse situations (Masten, 1994). These two components are elaborated in the next section below.

In general, there has been a trend in resilience research from defining it as a trait to regarding it as a dynamic process (Margalit, 2004). This shift from the "personal traits approach" to the "process approach" is based on a number of considerations. First, "resilience" is too broad a concept, and it is meaningful only when it relates to a specific context and specific outcomes. Second, the "process approach" gives researchers more insight into understanding the "dynamic and interactive" nature of the process, in which the protective mechanisms of protective factors operate and change to promote positive outcomes under negative circumstances. It has both theoretical and practical implications for resilience-based interventions. 


\section{Conceptualization of Two IMPORTANT COMPONENTS OF RESILIENCE}

The prevalence of resilience varies widely from $10 \%$ to $70 \%$ according to the findings reported in resilience literature (e.g. Grotberg; 2000; Kendall-Tackett, Williams, \& Finkelhor, 1993; Kim, 2001; Werner \& Smith, 1982). This wide variation in prevalence depends on two important components of resilience mentioned above, namely, extent of exposure to adversity or difficulty and the achievement of positive adaptation in the face of adversity or difficulty (Luthar et al., 2000a; Luthar \& Zigler, 1991; Masten, 1994; Masten et al., 1990; Rutter, 1990; Werner \& Smith, 1982).

\section{Risk Factors}

Risk factors of resilience refer to "variables that increase an individual's likelihood of psychopathology or their susceptibility to negative developmental outcomes" (Boyden \& Mann, 2000, p. 7). Risk factors may increase the probability of a negative outcome (Durlak, 1998). As argued by Masten (1994), risk is a statistical concept which is appropriately used for groups but not for individuals because actual outcomes of individual in the risk group may vary depending on diverse protective factors. From this point of view, risk factors increase the probability of an undesirable outcome, but it does not necessarily imply a causal relationship between them, which is difficult to verify (Masten \& Garmezy, 1985).

Resilience varies according to the nature and the number of risk factors, but there is no definite criterion to define a particular variable as a risk factor (Kaplan, 1999). There seems to be two types of risk factors in the resilience-related literature: individual attributes and environmental context (Clayton, 1992; Glantz \& Sloboda, 1999; Masten \& Garmezy, 1985). Kaplan (1999) further pointed out that risk status had often been defined in terms of the experience of adverse life events. Adversity includes physical and psychosocial adversities, which are psychological stressors varying from daily hassles to traumatic experiences (Masten, 1994). In empirical studies, descriptions of an adverse condition vary from a single stressful life experience to multiple negative events (Luthar, et al., 2000a). The majority of the resilience research focuses on the traumatic life events, such as poverty (Garmezy, 1991); childhood abuse (Kirby \& Fraser, 1997; McGloin \& Widom, 2001); burn survival (Holaday \& McPhearson, 1997); and antigay campaigns for lesbian, gay, and bisexual people (Russell \& Richards, 2003) - especially those that occur during childhood. However, Miller (2003) argued that resilient behavior will occur if an individual tries his/her best to make good use of available resources to overcome a series of personal setbacks in his/her life, such as marital or financial difficulties.

Three broad approaches have been used to operationalize psychosocial risk factors in empirical studies: multiple-item measures of risk, specific life stresses, and constellations of multiple risks (Luthar \& Cushing, 1999). Based on a thorough review of 1,200 prevention outcome studies, Durlak (1998) reported six levels of risk factors for youth: community, school, peer, family, individual, and other risk factors. Stress was considered to occur at all levels and affect individuals directly or indirectly in Durlak's analysis and is considered as one of the risk factors for poor mental health outcomes (Garmezy \& Devine, 
1984; Glantz \& Sloboda, 1999; Masten \& Garmezy, 1985; Stoltz, 1997). Resilience is meaningful when individuals are exposed to the enormity of stress (Kaplan, 1999), but stress needs to be concretely identified in a particular stressful condition (Glantz \& Sloboda, 1999).

\section{Outcome Variables: Maladaptation vs. Positive Adaptation}

Determining the criteria of positive or successful adaptation after experiencing adversity and difficulty is one of the fundamental issues in resilience research (Miller, 2003). Resilience varies according to diverse outcomes which may be determined in specific adverse contexts (Kaplan, 1999), so the outcomes of specific spheres of successful adaptation must be carefully appraised (Luthar, 1993). Like the definition of risk factor, a variety of definitions of positive adaptation have been suggested (Luthar, et al., 2000a). Diverse criteria have been used to evaluate good adaptation in resilience research (Masten \& Reed, 2002).

\section{The Absence of Psychopathology as Outcome Measures}

In some resilience research (e.g. Rutter, 1982; Rutter \& Quinton, 1984), investigators used the absence of psychopathology or maladaptive behavior as the indicators of resilience against high-risk conditions. In the domain of emotional outcomes, a low level of depression or a lack of depressive symptom has been widely used as a criterion of positive adaptation outcomes among various populations (e.g. Childrey, 1989; Heilemann, Lee \& Kury, 2002; Miller \& Chandler, 2002). Even in the studies of emotional resilience, only the negative emotion of depression was assessed (Denny, Clark, Fleming, \& Wall, 2004). Some studies identified the absence of problem behaviors as positive adaptation outcome (e.g. Ackerman, Izard, Schoff, Youngstrom, \& Kogos, 1999; Fergusson \& Lynskey, 1996). However, the absence of an undesirable outcome does not necessarily imply the presence of the desirable one (Kaplan, 1999). For example, some studies found that resilient individuals continue to experience psychological and social problems (Cohen, 1999; Luthar, 1991; Werner, 1989). Therefore, as a result, the criterion of the absence of psychopathology or problem behavior appears insufficient as a good outcome measure of positive adaptation and need to be used with great caution.

\section{Positive Health and Competence as Outcome Measures}

More recent investigations use positive health and competence as outcome measures to correct the traditional neglect of successful adaptation under adverse conditions (Luthar \& Zigler, 1991). Researchers have "commonly defined resilient outcomes in terms of good mental health, functional capacity, and social competence"(Olsson, Bond, Burns, Vella-Brodrick, \& Sawyer, 2003, p. 2). Social competence is one of the indicators of positive adaptation outcome (Luthar, 1991). In defining social competence in children, Zigler and Trickett (1979) proposed two criteria of the construct: one is that it must meet societal expectancies; the other is that it should mirror the self-actualization or personal development of the human being. They also suggested several indices of social competence, including physical health; cognitive ability and school performance; and 
social, emotional, and motivational variables. Similarly Vaslow (2000) also argued that in addition to competence on behavioral indices, social competence measures should also include measurements of psychological adjustment and emotional health. Social competence is widely used as an outcome variable in the studies of resilience in children (e.g. Garmezy \& Devine, 1984; Garmezy, Masten, \& Tellegen, 1984; Masten et al., 1999). Since school competence is important for school children from a developmental perspective (Masten, Best, \& Garmezy, 1990), various measures in the studies of resilience in children or youth, such as academic performance, achievement test scores, and teacher and peer judgment (Fisher, Kokes, Coles, Perkins, \& Wynne, 1987; Masten, Best, \& Garmezy, 1990; Navarro, 2003), have been employed to assess school competence.

There is a consensus that the criteria of positive adaptation should include external adaptation, but whether the criteria should include good internal adaptation (such as positive psychological well-being versus emotional distress and problems) is controversial. Some researchers include emotional health and well-being as additional criteria of positive adaptation, but others regard them as predictors of resilience (Masten \& Reed, 2002). Luthar and Zigler (1991) found that overt social competence among highrisk individuals did not indicate superior adjustment on covert mental health indices. As stated by Masten (1994), historically, psychological adaptation had two major components: mental functioning and external behavior. According to Masten, internal health has been described in terms of psychological well-being, internal equilibrium and ego strength, and good overt adaptation has referred to competence and social adjustment. Overt behavioral adaptation and internal adaptation are not the same (Luthar \& Zigler, 1991). Norman (2000) also insisted that resilience should be measured by observable behavioral criteria which do not necessarily indicate good emotional health. Therefore, it seems much better to include both psychological and behavioral variables to represent positive adaptation.

\section{From a Single Index to Multiple Indices}

However, single indices of competence are insufficient to reflect the complexity of adequate adjustment (Fisher et al., 1987). Luthar and colleagues (2000a) suggested that the outcome variables in resilience research should involve both positive adjustment and reduction or absence of psychopathology. Thus, multiple adaptation outcomes have been proposed by researchers (e.g. Kaplan, 1999; Luthar, 1993). Most empirical studies of resilience adopted multiple indices as measures of adaptation, including both the assessment of psychopathology or problem behaviors and various indicators of competence.

Although the evaluation of outcome measures of resilience based on multidimensional and multiple methods are invaluable, Luthar and Cushing (1999) stressed the importance of carefully examining the component domains that aggregate to indicate the overall competence. When multiple outcomes are assessed, it is important to examine the major adaptation outcome separately in the particular domain because resilience is context-specific (Luthar et al., 2000a). 


\section{Contextual Specificity of Outcome Variable}

Indeed, there is much evidence that resilience is context-specific (Freitas \& Downey, 1998). The selection of the outcome variables must be conceptually guided by the nature and severity of the risk studied (Luthar, Cicchetti, \& Becker, 2000a). Luthar and Cushing (1999) noted that given the various indictors of adaptation, it is important to choose outcome variables according to the particular risk domain being studied. They further argued that the researchers should choose outcome variable that is most likely to be affected by the specific risk condition. A resilient individual in one risk situation may not show resilience in another (Luthar et al., 2000b). Thus, it is important for researchers to realize that the concept of "overall" resilience may be overly simplistic. Researchers need to specify various types of resilience according to different domains of successful adaptation, such as academic or educational resilience, social resilience, and emotional resilience (Luthar, 1993; Luthar \& Zigler, 1991; Olsson et al., 2003).

\section{Two Generations of Resilience Research}

\section{First generation of resilience research}

The task of the first generation of resilience research was to find out the protective factors related to resilience. The first generation researchers were led by such question as "Among high-risk populations, what distinguishes those who do well from those who do poorly?” (Infante \& Lamond, 2003, p. 69). In resilience research, protective factors refer to those factors which mitigate the negative impact of adverse conditions (Henderson \& Milstein, 2003). Because of the protective functions of protective factors, for resilient individuals, "the adaptational trajectory is more positive than would be the case if the protective factors were not operational” (Masten et al., 1990, p. 431).

In resilience literature, it is widely recognized that protective factors include both individual and environmental factors (Fonagy et al., 1994; Frieman 2001; Glantz \& Sloboda, 1999; Henderson \& Milstein, 2003; Masten, 1994; Masten \& Garmezy, 1985; Norman, 2000). Although resilience must be specific to particular risk situations as indicated before, indicators of resilience appears to share something common to predict resilience (Fonagy et al., 1994). In the past few decades, a large body of research has identified various common core protective factors related to person and environment which have been proven to promote resilience (Norman, 2000). The personal protective factors include such factors as effective problem-solving skills and coping strategies (e.g. Frieman, 2001; Grotberg, 2003; Masten \& Reed, 2002); self-efficacy (e.g. Masten \& Reed, 2002; Norman, 2000); internal locus of control, autonomy, and independence (e.g. Fonagy et al., 1994; Henderson \& Milstein, 2003); empathy (e.g. Benard, 1997; Frieman, 2001; Grotberg, 2003); sense of purpose and meaning for life and future (e.g. Benard, 1997; Masten \& Reed, 2002); and sense of humor (e.g. Frieman, 2001; Norman, 2000). These factors, as well as other personal factors, represent an individual's inner strengths that promote resilience (Grotberg, 2003). Environmental protective factors include factors at three levels: family, school, and community. Family-related factors include such factors 
as trust and close relationship within the family, high expectations, social support from family members, competent, loving and patient parent; effective parenting, socioeconomic advantages, healthy communication patterns, and respect for individuality and autonomy (Benard, 1997; Fonagy et al., 1994; Frieman, 2001; Grotberg, 2003; Masten, 1994; Masten \& Coatsworth, 1998; Masten \& Reed, 2002; Norman, 2000; Schwartz, Jacobson, Hauser \& Dornbush, 1989; Werner, 1989). School-related protective factors are such factors as effective schooling, connection to prosocial and rule-abiding peers, a network of friends, better educational experience, social support outside family, and good role models (Fonagy et al., 1994; Frieman, 2001; Grotberg, 2003; Masten \& Reed, 2002; Masten \& Coatsworth, 1998; Masten, 1994; Schwartz et al., 1989; Werner, 1989). The protective factors at the community level are those factors such as good community assets, external support systems, connections to prosocial organizations, involvement in religious activities and faith, and connection to other competent adults (Frieman, 2001; Grotberg, 2003; Masten, 1994; Masten \& Coatsworth, 1998; Masten \& Reed, 2002; Schwartz et al., 1989; Werner, 1989;). From these investigations, it seems that social support is a very important factor facilitating resilience which is related to all three environmental levels.

\section{Second Generation of Resilience Research}

The second generation of resilience research emerged in the 1990s. Evidences have accumulated to indicate the need to shift from looking for risk and protective factors of resilience to exploring the underlying processes of how the protective factors work to mitigate the negative effects of risk factors (Garmezy, 1991; Luthar, 1993; Rutter, 1987;). The second generation of resilience researchers emphasized that resilience is a process more than a list of traits (e.g. Henderson \& Milstein, 2003; Margalit, 2004). The process refers to the interaction between various risk and protective factors to achieve a positive adaptation outcome (Luthar et al., 2000a). This generation of researchers argued that resilience is the balance of the interaction between risk factors and protective factors (e.g. Grotberg, 2000; Werner \& Smith, 1982) which are directly associated with adaptation outcomes (Masten, 1994). Henderson and Milstein (2003) stated that when this balance is favorable, positive adaptation outcome is possible. Nevertheless, what the point of the balance is remains controversial and unclear. Wolin and Wolin (1993) indicated that even a single protective factor can propel a person to overcome a challenging or stressful environment. However, Werner (2000) argued that "when stressful life event outweigh the protective factors, even the most resilient child can develop problems" (p. 128). The larger the number of risk factors an individual encounters, the more likely he/she will respond poorly, rather than demonstrate resilience (Cowen, Wyman \& Parker, 1990; Norman, 2000). Masten, Best, and Garmezy (1990) also agued that although the protective factors may mitigate the negative effect of risk factors on individuals to achieve positive outcomes, they may not necessarily yield resilience if the severity of the adversity is too great to overcome. Unlike the first generation research which focused on the protective factors to promote resilience, the second generation focused on the protective process or mechanism that these factors "work" to promote resilience (Masten, 1999; Rutter, 1990). However, the protective mechanism and the interaction between protective 
factors and risk factors to promote resilience remained largely unknown (Doll \& Lyon, 1998; Durlak, 1998; Masten, 1994). There is a recent development to explore the protective mechanisms of various protective factors in resilience research (Minnard, 2002). Although we cannot change the risk factors and make stress disappear, the goal of resilience research is to enhance protective factors to help people become more resilient (Frieman, 2001; Henderson \& Milstein, 2003).

\section{Cultural Concern in Resilience Research}

Grotberg was one of the first researchers to question the cultural specificity of resilient adaptation (Infante \& Lamond, 2003). In 2000, she started to ask whether resilience varied among different cultures and conducted research in 22 countries to address this question. She found both differences and similarities in the protective factors of resilience. For example, she reported that the common protective factors across cultures included such factors as providing loving support, being role models, seeking help, conducting responsible behaviors, and having problem-solving skills. She argued that cultural differences and similarities did not mitigate against the promotion of resilience, and that it was important to explore which protective factors work within a specific cultural context. Montgomery, Burr and Woodhead (2003) also suggested that resilience research on risk factors and protective factors should be conducted in a cultural context because a particular risk or protective factor in one culture will not necessarily have the same effect on individuals in another culture. Some researchers (Kaplan, 1999; Masten, 1994) have also suggested taking into consideration the cultural component in future resilience studies. Chan and Chan (2001) indicated that in Chinese society, resilience was seen as a transformation through pain into a new source of energy. They further related the concept of resilience to the Eastern Buddhism ideas of nonattachment and nothingness, and the Taoism teaching of letting go and accepting life as ever-changing and unpredictable. They argued that the richness of the mixture of traditional cultural values and contemporary belief systems will help us understand resilience in an Asian environment.

\section{STUdies OF Resilience in ASIAn Societies}

There are very few published studies of resilience in Asian societies. These studies cover three main areas of resilience research: individual resilience, family resilience and measurement of resilience.

\section{Individual Resilience}

The studies of individual resilience in Asian societies mainly focus on the protective factors that may promote resilience among Asians, especially Chinese populations. Many of these protective factors reported in Asian societies are similar to those reported in 
Western countries with few factors specified in the context of their own cultures. Similar to the findings in the West, Ho, Zhu, Lin, Huang and Zhao (2002) found that the resilience of Hong Kong people is associated with interpersonal ability, the ability to deal with crises independently, and sense of humor. In addition to individual protective factors, some environmental factors have also been reported among Chinese populations. For example, in a study of risk and resilience to adolescent substance abuse in Hong Kong, Chan, Day and Chau (1999) found that there were significant group differences between substance abusers and non-abusers in spending habits, school environment, peer association and family variables, such as family structure, parent's marital relationship, family cohesion, and parent-child communication and relationship.

\section{Family Resilience}

Family resilience has been found in Chinese society. In a study of 1,015 telephone interviews seeking to understand how the Hong Kong families are affected by joblessness, Ma, Wong and Lau (2003) found that more than half of the interviewees felt overall satisfaction with family life during an economic recession, which indicated the high resilience of Hong Kong family.

A few studies of family resilience in Asian societies have investigated the protective factors that might enhance family resilience. A case study conducted by Osman, Li and Suppien (2001) revealed that families experiencing life stressors and crisis in Singapore built up their resilience through both intrapersonal factors such as self-control, sense of mastery, hardiness, and learned resourcefulness, and interpersonal factors such as social support and the availability of social networks. Similarly, Nair, Tai and Fong (2001) found that factors contributing to the resilience of children in violent families in Singapore appeared to include: (1) a positive parent-child relationship; (2) the presence of a caring adult; (3) reaching high levels of academic achievement in school; (4) individual characteristics such as interpersonal skills, reflectiveness, good-natured temperament, and sense of humor; (5) taking responsibility for the abuse; and (6) having access to and knowledge of external resources. The role of family was emphasized as an important social network for families facing adversity (Ma et al., 2003). In addition to the most frequently reported factors in western literature, culture-related factors have also been found by one study in an Asian society. Kasmani and Ow (2001) found that besides the internal strength of the individual and social support, the Malay/Muslim worldviews, such as the permissibility of divorce in Islam, a strong spiritual relationship with God, and caring for the community were important protective factors that facilitate the resilience of children in divorced Malay-Muslim families. Unfortunately, these culture-specific factors that are unique and important to Asian societies have seldom been investigated in the literature, especially in Chinese society.

\section{Measurement of Resilience}

Researchers have regarded resilience as a personal trait in the studies of measurement of resilience in Asian societies. Two instruments have been developed to measure the resilience of Chinese people. The first one is a 10-item questionnaire developed by Ho, 
Zhu, Lin, Huang, and Zhao (2002). They extracted three factors of resilience by factor analysis: personal ability, personal flexibility, and self-image. Personal ability included interpersonal ability, the ability to deal with crisis independently, and sense of humor. No reliability and validity of the questionnaire has been reported. The second one is a 44-item questionnaire developed by Lau (2003) to measure resilience among Chinese students in six dimensions: anger management, conflict resolution, problem-solving, goal setting, optimism, and belongingness. The reliability of the scale has been shown to be acceptable, but no validity has been reported for this questionnaire. In fact, the factors measured in these two questionnaires are the individual protective factors to promote resilience. More studies of scale construction for measuring resilience need to be carried out to differentiate between resilience as a personal trait and the protective factors that promote resilience in Asian Societies.

\section{IMPLICATIONS OF RESILIENCE RESEARCH}

Resilience research has both theoretical and practical implications. From the theoretical perspective, the study of resilience adopts the strength perspective of positive psychology. It goes against the traditional notion that adversity will inevitably lead to psychosocial pathology and demonstrates the possibility and process of positive adaptation outcomes in diverse adverse contexts. Theoretical issues regarding the mechanism of interaction between risk and protective factors in the development of resilience, the possibility of growth beyond resilience, and the possibility of the coexistence of resilience and psychosocial malfunctioning in Chinese societies would be interesting subjects for future research. Practically, resilience research provides an theoretical basis for designing resilience-based interventions that adopt a holistic approach. Though it may be difficult to alter many of the risk factors discussed above, it should be possible to enhance various protective factors at both individual and environmental levels to promote positive adaptation in a variety of high-risk populations. Furthermore, culturally relevant intervention outcome measures need to be developed to make evidence-based resilience interventions possible.

\section{REFERENCE}

Ackerman, B., Izard, C., Schoff, K., Youngstrom, E., \& Kogos, J. 1999. Contextual risk, caregiver emotionality, and the problems behaviours of six- and seven-year-old children from economically disadvantaged families. Child Development, 70, 1415-1427.

Benard, B. 1997. Fostering resiliency in children and youth: Promoting protective factors in the school. In D. Saleebey (Ed.), The strengths perspective in social work practice.USA:Longman Publishers.

Block, J. H., \& Block, J. 1980. The role of ego-control and ego-resiliency in the organization of behavior. In W. A. Collins (Ed.), Minnesota symposia on child psychology (Vol. 13, pp. 39-101). Hillsdale, NJ: Erlbaum.

Boyden, J., \& Mann, G. 2000. Children's risk, resilience and coping in extreme situations. Background paper to the consultation on Children in Adversity, Oxford, UK.

Chan, C. L. W., \& Chan, E. K. L. 2001. Enhancing resilience and family health in the asian context. Asia 
Pacific Journal of Social Work, 11, 5-17.

Chan, W. M., Day, J., \& Chau, A. 1999. Family and peer variables related to the risk for and resilience to adolescent substance abuse. In Symposium on children's agenda for hong kong in the 21st century (pp. 14). Hong Kong: The Save the Children Fund (Hong Kong) \& Faculty of Social Sciences, The University of Hong Kong. (Proceedings)

Childrey, G. J. 1989. Resilience and risk: Personality and characteristics as measured by the rorschach. Dissertation Abstracts International: Section B, 49, 4591.

Clayton, R. R. 1992. Transitions in drug use: Risk and protective factors. In M. D. Glantz \& R. W. Pickens (Eds.), Vulnerability to drug abuse (pp. 15-51). Washington, DC: American Psychological Association.

Cohen, E. C. 1999. Perceived social support as protective factor in manifest resilience and emotional resilience. Dissertation Abstracts International Section B: The Sciences and Engineering, 59, 3685.

Cowen, E. P., Wyman, W. W., \& Parker, G. 1990. The rochester child resilience project: Overview and summary of first year findings. Development and Psychopathology, 2, 193-212.

Denny, S., Clark, T. C., Fleming, T., \& Wall, M. 2004. Emotional resilience: Risk and protective factors for depression among alternative education students in new zealand. American Journal of Orthopsychiatry, 74, 137-149.

Doll, B., \& Lyon, M. A. 1998. Risk and resilience: Implications for the delivery of educational and mental health services in schools. School Psychology Review, 27, 348-364.

Durlak, J. A. 1998. Common risk and protective factors in successful prevention programs. American Journal of Orthopsychiatry, 68, 512-520.

Fergusson, D. M., \& Lynskey, M. T. 1996. Adolescent resiliency to family adversity. Journal of Child Psychology and Psychiatry, 37, 281-292.

Fisher, L., Kokes, R. F., Coles, R., Perkins, P. M., \& Wynne, L. C. 1987. Competent children at risk: A study of well-functioning offspring of disturbed parents. In E. J. Anthony \& B. Cohler (Eds.), The invulnerable child (pp. 211-228). New York: The Guilford Press.

Fonagy, P., Steele, M., Steele, H., Higgitt, A., \& Target, M. 1994. The emanuel miller memorial lecture 1992: The theory and practice of resilience. Journal of Child Psychology and Psychiatry, 35, 231-257.

Freitas, A. L., \& Downey, G. 1998. Resilience: A dynamic perspective. International Journal of Behavioral Development, 22, 263-285.

Frieman, B. 2001. What teachers need to know about children at risk.New York: McGraw-Hill.

Garmezy, N. 1991. Resilience and vulnerability to adverse developmental outcomes associated with poverty. American Behavioral Scientist, 34, 416-430.

Garmezy, N., \& Devine, V. T. 1984. Project competence: The Minnesota studies of children vulnerable to psychopathology. In N. Watt, E. J. Anthony, L. C. Wynne \& J. E. Rolf (Eds.), Children at risk for schizophrenia (pp. 289-303). Cambridge: Cambridge University Press.

Garmezy, N., Masten, A. S., \& Tellegen, A. 1984. The study of stress and competence in children: A building block for developmental psychopathology. Child Development, 55, 97-111.

Glantz, M. D., \& Sloboda, Z. 1999. Analysis and reconceptualization of resilience. In M. D. Glantz \& J. L. Johnson (Eds.), Resilience and development: Positive life adaptation. New York: Plenum.

Grotberg, E. H. 2000. The international resilience research project. In A. L. Comunian \& U. Gielen (Eds.), International perspectives on human development (pp. 379-399). Lengerich: Pabst Science Publishers.

Grotberg, H. E. 2003. Resilience for today: Gaining strength from adversity. Westport, Conn.: Praeger Publishers.

Heilemann, M. V., Lee, K. A., \& Kury, F. S. 2002. Strengths and vulnerabilities of women of mexican descent in relation to depressive symptoms. Nursing Research, 51, 175-182.

Henderson, N., \& Milstein, M. M. 2003. Resiliency in schools: Making it happen for students and educators. Thousand Oaks, CA: Corwin Press.

Ho, G. L., Zhu, Y. K., Lin, G. W., Huang, W. C., \& Zhao, L. Z. 2002. Research on resilience of Hong Kong people. Hong Kong: St. James' Settlement \& Poly University of Hong Kong (in Chinese).

Holaday, M., \& McPhearson, R. W. 1997. Resilience and server burns. Journal of Counseling and Development, 75, 346-356.

Infante, F., \& Lamond, A. 2003. Resilience and biculturalism: The latino experience in the united states. In E. H. Grotberg (Ed.), Resilience for today: Gaining strength from adversity. Westport, Conn.: Praeger 
Publishers.

Kaplan, H. B. 1999. Toward an understanding of resilience: A critical review of definitions and models. In M. D. Glantz \& J. L. Johnson (Eds.), Resilience and development: Positive life adaptation (pp. 17-84). New York: Plenum.

Kasmani, S. S., \& Ow, R. 2001. Worldviews and resilience in children of divorced families. Asia Pacific Journal of Social Work, 11(Special Issue), 37-50.

Kendall-Tackett, K. A., Williams, L. M., \& Finkelhor, D. 1993. Impact of sexual abuse on children: A review and synthesis of recent empirical studies. Psychological Bulletin, 113, 164-180.

Kim, E. 2001. Korean-american parent-child relationships, parental acculturation, and young adolescents' psychosocial functioning. Dissertation Abstracts International Section B: The Sciences and Engineering, 62, 1806.

Kirby, L., \& Fraser, M. W. 1997. Risk and resilience in childhood. In M. W. Fraser (Ed.), Risk and resilience in childhood: An ecological perspective.Washington, DC: NASW Press.

Lau, J. T. F. 2003. Report on evaluation of the uniderstanding the adolescent project (uap) in secondary schools 2001/02. Hong Kong: School of Public Health, Faculty of Medicine, The Chinese University of Hong Kong.

Liddle, H. A. 1994. Contexualizing resilience. In M. C. Wang \& E. W. Gordon (Eds.), Educational resilience in inner-city america: Challenges and prospects (pp. 167-190). New Jersey: Lawrence Erlbaum Associations.

Liem, J. H., James, J. B., O’Toole, J. G., \& Boudewyn, A. C. 1997. Assessing resilience in adults with histories of childhood sexual abuse. American Journal of Orthopsychiatry, 67, 594-606.

Lopez, S. J., Prosser, E. C., \& Edwards, L. M. 2002. Putting positive psychology in a multicultural context. In C. R. Snyder \& S. J. Lopez (Eds.), Handbook of positive psychology (pp. 700-714). New York: Oxford University Press.

Luthar, S. S. 1991. Vulnerability and resilience: A study of high risk adolescents. Child Development, 62, $600-616$.

Luthar, S. S. 1993. Annotation: Methodological and conceptual issues in research on child resilience. Journal of Child Psychology and Psychiatry, 34, 441-453.

Luthar, S. S., Cicchetti, D., \& Becker, B. 2000a. The construct of resilience: A critical evaluation and guidelines for future work. Child Development, 71, 543-562.

Luthar, S. S., Cicchetti, D., \& Becker, B. 2000b. Research on resilience: Response to commentaries. Child Development, 71, 573-575.

Luthar, S. S., \& Cushing, G. 1999. Measurement issues in the empirical study of resilience. In M. D. Glantz \& J. L. Johnson (Eds.), Resilience and development: Positive life adaptation (pp. 129-160). New York: Kluwer Academic/Plenum Publishers.

Luthar, S. S., \& Zigler, E. 1991. Vulnerability and competence: A review of research on resilience in childhood. American Journal of Orthopsychiatry, 61, 6-22.

Ma, L. C., Wong, K. Y. T., \& Lau, Y. K. 2003. Family resilience under the condition of economic recession. Hong Kong: Hong Kong Institute of Asia-Pacific Studies.

Margalit, M. 2004. Second-generation research on resilience: Social-emotional aspects of children with learning disabilities. Learning Disabilities Research \& Practice, 19, 45-48.

Masten, A. S. 1994. Resilience in individual development: Successful adaptation despite risk and adversity. In M. C. Wang \& E. W. Gordon (Eds.), Educational resilience in inner-city america: Challenges and prospects (pp. 3-25). New Jersey: Lawrence Erlbaum Associates, Inc.

Masten, A. S. 1999. Resilience comes from age: Reflections on the past and outlook for the next generation of research. In M. D. Glantz, J. Johnson \& L. Huffman (Eds.), Resilience and development: Positive life adaptations (pp. 281-296). New York: Plenum.

Masten, A. S., Best, K. M., \& Garmezy, N. 1990. Resilience and development: Contributions from the study of children who overcome adversity. Development and Psychopathology, 2, 425-444.

Masten, A. S., \& Coatsworth, J. 1998. The development of competence in favorable and unfavorable environments: Lessons from research on successful children. American Psychologist, 53, 205-220.

Masten, A. S., \& Garmezy, N. 1985. The risk, vulnerable, and protective factors in developmental psychopathology. In B. B. Lahey \& A. E. Kazdin (Eds.), Advances in clinical child psychology (Vol. 8, pp. 1-52). New York and London: Plenum Press.

Masten, A. S., Hubbard, J. J., Gest, S. D., Tellegen, A., Garmezy, N., \& Ramirez, M. 1999. Competence in 
the context of adversity: Pathways to resilience and maladaptation from childhood to late adolescence. Development and psychopathology, 11, 143-169.

Masten, A. S., \& Reed, M. G. J. 2002. Resilience in development. In C. R. Snyder \& S. J. Lopez (Eds.), Handbook of positive psychology (pp. 74-88). New York: Oxford University Press.

McGloin, J. M., \& Widom, C. S. 2001. Resilience among abused and neglected children grown up. Development and psychopathology, 13, 1021-1038.

Miller, A. M., \& Chandler, P. J. 2002. Acculturation, resilience, and depression in midlife women from the former soviet union. Nursing Research, 51, 26-32.

Miller, E. D. 2003. Reconceptualizing the role of resiliency in coping and therapy. Journal of Loss and Trauma, 8, 239-246.

Minnard, C. V. 2002. A strong building: Foundation of protective factors in schools. Children \& Schools, 24, 233-246.

Montgomery, H., Burr, R., \& Woodhead, M. 2003. Changing childhoods: Local and global.Chichester: John Wiley \& Sons.

Nair, S., Tai, P. K., \& Fong, S. S. 2001. Children's resilience in living in violent families. Asia Pacific Journal of Social Work, 11(Special Issue), 63-77.

Navarro, G. J. 2003. The factors of resilience contributing to the academic success of adult survivors of child maltreatment. Unpublished Ph.D. thesis, Azusa Pacific University.

Norman, E. 2000. Resiliency enhancement: Putting the strengths perspective into social work practice. New York: Columbia University Press.

Olsson, C. A., Bond, L., Burns, J. M., Vella-Brodrick, D. A., \& Sawyer, S. M. 2003. Adolescent resilience: A concept analysis. Journal of Adolescence, 26, 1-11.

Osman, M. M. B., Li, C. S., \& Suppien, S. M. 2001. Resilience in families at risk: Giving a healthy start to their children. Asia Pacific Journal of Social Work, 11(Special Issue), 18-36.

Russell, G. M., \& Richards, J. A. 2003. Stressor and resilience factors for lesbians, gay men, and bisexuals confronting antigay politics. American Journal of Community Psychology, 31, 313-328.

Rutter, M. 1982. Epidemiological-longitudinal approaches to the study of development. In W. A. Collins (Ed.), The concept of development, minnesota symposia on child psychology (Vol. 15, pp. 105-144). Hillsdale, NY: Lawrence Erlbaum.

Rutter, M. 1987. Psychosocial resilience and protective mechanisms. American Journal of Orthopsychiatry, 57, 316-331.

Rutter, M. 1990. Psychosocial resilience and protective mechanisms. In J. E. Rolf \& A. S. Masten (Eds.), Risk and protective factors in the development of psychopathology (pp. 181-214). New York: Cambridge University Press.

Rutter, M., \& Quinton, D. 1984. Long-term following up of women institutionalized in childhood: Factors promoting good functioning in adult life. British Journal of Developmental Psychology, 18, 225-234.

Schwartz, J. M., Jacobson, A. M., Hauser, S. T., \& Dornbush, B. B. 1989. Explorations of vulnerability and resilience: Case studies of diabetic adolescents and their families. In T. F. Dugan \& R. Coles (Eds.), The child in our times: Studies in the development of resiliency (pp. 134-156). New York: Brunner/ Mazel.

Stoltz, P. G. 1997. Adversity quotient: Turning obstacles into opportunities.New York: Wiley.

Vaslow, M. A. 2000. Educational resiliency: The effect of motivation on academic achievement. Unpublished $\mathrm{Ph}$. D. thesis, Tulane University.

Werner, E. E. 1989. High-risk children in young adulthood: A longitudinal study from birth to 32 years. American Journal of Orthopsychiatry, 59, 72-81.

Werner, E. E. 2000. Protective factors and individual resilience. In J. P. Shonkoff \& S. J. Meisels (Eds.), Handbook of early childhood intervention (pp. 115-134). New York: Cambridge University Press.

Werner, E. E., \& Smith, R. 1982. Vulnerable but invincible.New York: McGraw-Hill.

Wolin, S. J., \& Wolin, S. 1993. The resilient self: How survivors of troubled family rise above adversity. New York: Villard.

Zigler, E., \& Trickett, P. K. 1979. The concept of competence and national social policy in the child and family area. In N. W. Kent \& J. E. Rolf (Eds.), Primary prevention of psychopathology (Vol. 3, pp. 280-296). Hanover, NH: University Press of New England. 